Retrospective Audit

\title{
Intramuscular Botulinum Toxin in Complex Regional Pain Syndrome: Case Series and Literature Review
}

Siddharth Kharkar, MD, Prakash Ambady, MD, Yedatore Venkatesh, MD, and Robert J. Schwartzman, MD

From: Drexel University College of Medicine, Philadelphia, PA; and Hahnemann University Hospital, Philadelphia, PA.

Dr. Kharkar is Resident in Neurology, Department of Neurology, Drexel College of Medicine and Hahnemann University Hospital, Philadelphia, PA. Dr. Ambady is Resident in Neurology, Department of Neurology, Drexel College of Medicine and Hahnemann University Hospital, Philadelphia, PA Dr. Yedatore is a Professor in the Department of Neurology at Drexel University College of Medicine, Philadelphia, PA.

Dr. Schwartzman is Professor

and Chairman of the Department

of Neurology at Drexel University College of Medicine, and Hahnemann

University Hospital, Philadelphia, PA.

Address correspondence: Robert Schwartzman, MD Drexel University College of Medicine 219 N Broad St, 7th Fl Philadelphia, PA 19107 E-mail:

Robert.Schwartzman@DrexelMed.edu

Disclaimer: There was no external funding in the preparation of this manuscript.

Conflict of interest: None.

Manuscript received: 12/07/2010 Revised manuscript received: 03/18/2011 Accepted for publication: 05/04/2011

Free full manuscript: www.painphysicianjournal.com
Background: Pain associated with Complex Regional Pain Syndrome (CRPS) is frequently excruciating and intractable. The use of botulinum toxin for relief of CRPS-associated pain has not been well described.

Objectives: To assess whether intramuscular botulinum toxin injections cause relief of pain caused by CRPS, and to assess the risks of this treatment.

Study Design: Retrospective chart review.

Setting: Outpatient clinic

Methods: Thirty-seven patients with spasm/dystonia in the neck and/or upper limb girdle muscles.

Intervention: EMG-guided injection of Botulinum toxin - A (BtxA), 10-20 units per muscle. Total dose used was 100 units in each patient. Local pain score was measured on an 11-point Likert scale, 4 weeks after BtxA injections.

Results: Mean pain score decreased by $43 \%(8.2 \pm 0.8$ to $4.5 \pm 1.1, P<0.001) .97 \%$ of patients had significant pain relief. One patient had transient neck drop after the injections.

Limitations: This is a retrospective study. It lacks a control group and so the placebo effect cannot be eliminated. This study does not provide information on the efficacy of this treatment after 4 weeks.

Conclusions: Intramuscular injection of botulinum toxin in the upper limb girdle muscles was beneficial for short term relief of pain caused by CRPS. The incidence of complications was low $(2.7 \%)$

Institutional Review: This study was approved by the Institutional Review Board of the Drexel College of Medicine.

Key words: Complex regional pain syndrome, botulinum toxin, spasm, dystonia

Pain Physician 2011; 14:419-424 omplex Regional Pain Syndrome (CRPS) is an incompletely understood, frequently Jdevastating condition characterized by severe neuropathic pain. Associated features include autonomic dysregulation (increased sweating, increased temperature of the affected area, edema), motor symptoms (weakness, tremor, dystonias) and trophic changes (e.g., loss of hair, nail changes, skin atrophy) $(1,2)$. The exact pathophysiology of CRPS is not known. Sensitization of the nociceptive system, 
both peripherally and centrally, is believed to be a key pathogenic process (3). The frequently excruciating pain is difficult to treat, and the natural history of CRPS is marked by unremitting worsening of the pain (1) .

The most widely known action of Botulinum toxin A (BtxA) is its relaxing effect on skeletal muscles. BtxA is therefore widely used for the symptomatic relief of spasticity, dystonias, and other movement disorders. Recently there has been great interest in the use of BtxA for chronic pain. This interest stems from the fact that BtxA seems to have an early anti-nociceptive action that is independent of its muscle relaxing action and may be due to inhibition of central and peripheral sensitization (4-9). It has been previously hypothesized that the anti-nociceptive action of BtxA may be beneficial in CRPS (10) .

We conducted a retrospective chart review of CRPS patients with pain and dystonia of neck and upper limb girdle muscles treated with intramuscular BtxA injections to ascertain the benefits and risks of this treatment.

\section{Methods}

Thirty-seven patients were included in the study of whom 35 ( 95\%) were females. All participants in this study were initially seen in the pain clinic, and had CRPS as their primary diagnosis. All patients met the IASP criteria for CRPS (11) with 26/37 (70\%) of participants diagnosed with CRPS Type 1, and 11/37 (30\%) of participants with CRPS Type 2 . Ten (27\%) of the participants had localized CRPS predominantly involving one or both upper limbs. CRPS involved the entire body in $27(73 \%)$ of the patients.

Participants with spasm or dystonia in the upper limb girdle muscles were referred for BtxA treatment. Based on previous literature, it was believed that participants with spasm/dystonia in the upper limb girdle muscles were most likely to benefit from BtxA treatment. These participants subsequently had electromyography (EMG) guided BtxA injections into these muscles.

\section{Botulinum injections}

Participants were treated with intramuscular BtxA injections into specific upper limb girdle and neck muscles. EMG was utilized for injection of BtxA into the targeted muscles. Muscles were selected by patient complaints, hypertrophy, spasm and/or tenderness on palpation. The injecting needle also functioned as a monopolar recording electrode, and the reference
Table 1. Muscles injected with Botulinum Toxin A

\begin{tabular}{|l|c|c|}
\hline Muscle & Number & Percentage \\
\hline 1. Trapezius & 37 & 100 \\
\hline 2. Splenius Capitis & 37 & 98 \\
\hline 3. Levator Scapulae & 35 & 95 \\
\hline 4. Longissimus Capitis & 17 & 46 \\
\hline 5. Obliqus Capitis & 13 & 35 \\
\hline 6. Scalene & 12 & 32 \\
\hline 7. Semispinalis & 12 & 32 \\
\hline 8. Obliqus Capitis & 13 & 35 \\
\hline 9. SCM & 4 & 11 \\
\hline 10. Paraspinals, not specified & 4 & 11 \\
\hline
\end{tabular}

electrode and ground electrode was a surface electrode placed close by. The needle was inserted into the targeted muscle using bony and soft tissue landmarks. The position of the needle in the targeted muscle was confirmed by asking the participants to activate the muscle and confirming the presence of motor unit potentials on the EMG monitor. Based on the size of the muscle, 10-20 units of BtxA were then injected through the needle. This procedure was repeated for all muscles injected. The total amount of BtxA used per participant was 100 units.

The majority of participants were injected on only one side - the right side in $15(41 \%)$, and the left in 17 $(46 \%)$. Eight $(22 \%)$ had bilateral injections. The specific sites of injection are listed in Table 1.

\section{Pain-scores}

Pain scores were recorded based on the participant's report of local pain on an 11-point Likert scale, where a score of zero meant the participant had no pain, and a score of 10 was the worst pain imaginable. Pre-treatment pain scores were collected immediately prior to the injections. Post-treatment pain scores were collected 4 weeks after the BtxA injections. None of the study participants had significant medication changes in the 4 weeks after BtxA injection. Participants who had significant medication changes, or had possible disease modifying treatments such as ketamine infusions, were excluded from this study. A participant was classified as "improved" if the decrease in pain scores was 2 or more. This was based on the results of a recent meta -analysis of pain studies by Farrar et al (12) that demonstrated a 2 point decrease to be clinically significant. 


\section{Statistical Analysis:}

All statistical analysis was done using STATA 9 (StataCorp, College Station, TX). The student t-test was used for comparing means, the rank-sum test was used for comparing continuous variables for small samples, and the chi-square test was used for comparing proportions.

\section{IRB Approval:}

This study was approved by the Institutional Review Board of the Drexel College of Medicine.

\section{Results}

\section{Pain relief}

All participants reported severe local pain at baseline, which was $8.2 \pm 0.8$ (range 7 to 10 ). The mean local pain score after the BtxA was $4.5 \pm 1.1$ (range 2 to 8 ). On an average, there was a $43 \%$ (range $11 \%$ to $78 \%$ ) decrease in local pain scores. This difference was statistically significant $(P<0.001)$. These results are illustrated in Fig. 1.
By Farrar's criterion (i.e., a decrease in local pain score by 2 or more points), 36/37 participants (97\%) reported significant improvement in local pain.

\section{Side-effects:}

One out of the 37 participants $(2.7 \%)$ developed a transient neck drop after BtxA injection. This participant required a non-invasive plastic neck brace after BtxA injections. The neck drop resolved spontaneously 2 weeks after the BtxA injection without any further complications.

None of the participants reported new onset dysphagia after the injections. No other serious side-effects developed after the intramuscular BtxA injections.

\section{Factors affecting improvement:}

Age, sex, extent of CRPS, CRPS type, number of extremities affected, and the duration of disease were not found to affect the magnitude of pain decrease seen after BtxA injections.

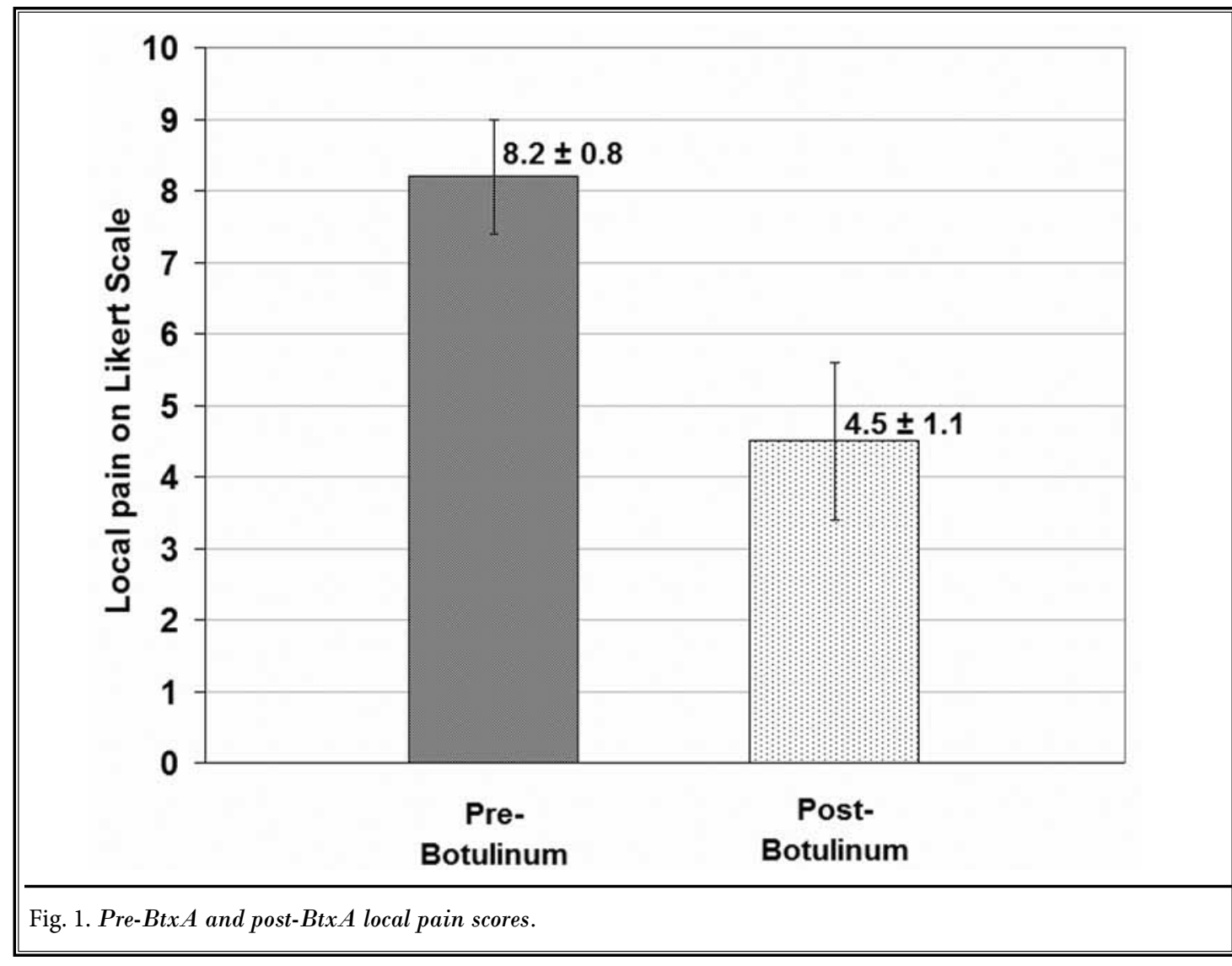




\section{Discussion}

In this retrospective study, we found that intramuscular injection of botulinum toxin in the upper limb girdle muscles was beneficial for short term relief of pain caused by CRPS. Participants in this study were diagnosed with CRPS by strict application of IASP criteria by a single expert (RJS), minimizing diagnostic variability. All EMG-guided BtxA injections were administered by a single individual, who was well acquainted with the procedure. There was a $43 \%$ decrease in local pain scores 4 weeks after intramuscular BtxA injections. The incidence of serious side effects associated with this therapy was low (2.7\%). There was no clinical prognostic marker for success of treatment. A previous study of the natural history of CRPS demonstrated little change of symptom severity after 1 year (1)

In most patients, CRPS is initiated by trauma to the body, a surgical procedure or fracture (1). The inciting event can produce neuropathic pain by peripheral and central sensitization. Peripheral sensitization lowers the threshold for nociceptor discharge by inducing changes in the receptors themselves (autosensitisation) and/or by increasing the excitability of the pain terminal membrane (heterosensitisation) (13). In CRPS, there is evidence of immune mediated inflammation, a process which is likely to be self-sustaining (3). Substance P and CGRP peptides are the vasoactive neuropeptides thought to be most active in the process of neurogenic inflammation $(2,14)$ which might also enhance the "afferent barrage" to the dorsal root ganglia (DRG) and dorsal horn of the spinal cord. This induces central sensitization of pain transmission neurons which is pivotal to the maintenance of neuropathic pain $(3,13)$.

Botulinum Toxin A acts by cleaving the SNAP-25 (Synaptosome-associated protein of $25 \mathrm{kd}$ ) complex in the presynaptic terminal, which prevents formation of the SNARE (soluble N-ethyl malemide sensitive factor-attachment protein-receptor) system. As a consequence, neurotransmitter vesicles do not fuse with the presynaptic membrane, which decreases the release of neurotransmitters at the synaptic cleft. This mechanism decreases the release of acetylcholine, CGRP, substance$P$ and glutamate which may decrease the nociceptive fiber discharge $(9,15-17)$.

Dystonia occurs in approximately $20 \%$ of CRPS patients $(18,19)$. This abnormal, sustained contraction of skeletal muscles can reasonably be assumed to be a significant source of pain in CRPS patients.
In the past, intrathecal baclofen and intrathecal glycine have been evaluated for relief of CRPS associated dystonia. In larger case series, the former was found to be effective $(20,21)$, but was associated with a high complication rate in at least one study (21); while the latter was ineffective in relieving either pain or dystonia (22). In our study, we postulate that the relief of CRPS induced pain by intramuscular BtxA injection is multifactorial: 1) relief of neurogenic inflammation (23-25), 2) relaxation of dystonic muscles that may decrease the afferent nociceptive barrage from sensitised A-delta and C fibers, 3) a distinct antinociceptive action which is distinct from these above mentioned mechanisms (4-6) .

There are a significant number of clinical studies on the use of BtxA in neuropathic pain, that includes 2 recent randomized controlled trials. Yuan et al (26) demonstrated in a placebo-controlled randomized trial of 18 patients that intradermal BtxA is effective in relieving painful diabetic neuropathy with results showing $44 \%$ of patients receiving BtxA reporting significant relief of pain, as compared to $0 \%$ in the placebo group. Ranoux et al (6), in another placebo-controlled randomized trial of 29 patients, showed that intradermal BtxA was effective in post-herpetic neuralgia or posttraumatic/postoperative neuropathic pain. In this study, $40 \%$ of patients receiving BtxA reported significant improvement at the end of 2 weeks, as compared to $14 \%$ of the patients receiving placebo. The relief of pain was sustained for 6 months after the initial injection. Multiple other non-randomized studies demonstrating the antinociceptive action of BtxA in neuropathic pain caused by diverse clinical conditions have been summarized (27).

In contrast, the use of BtxA for pain relief in CRPS has only been described in 5 small studies, which are summarized in Table 2.

In contrast to earlier studies of BtxA in CRPS, a recent randomized trial failed to find improvement in pain after intradermal BtxA injections (29). The authors postulated that failure was due to the very severe/advanced nature of CRPS in their study participants, and the mode of administration of BtxA (intradermal-subcutaneous rather than intramuscular). This study was followed up quickly by the same group by a small case series describing 2 patients who were treated with intramuscular instead of intradermal BtxA (28). Both patients had improvement in pain, skin discoloration and swelling which is in agreement with the earlier study by Argoff (10). 
Table 2. Previous literature on botulinum use for pain relief in CRPS.

\begin{tabular}{|c|c|c|c|c|c|}
\hline Study & $\begin{array}{l}\text { Treated } \\
\text { CRPS } \\
\text { patients }\end{array}$ & Controls & Treatment & Results & Comments \\
\hline $\begin{array}{l}\text { Safarpour } \\
2010(28)\end{array}$ & $\begin{array}{l}2 \text { participants. } \\
\text { One with } \\
\text { right hand, } \\
\text { and the other } \\
\text { with left hand } \\
\text { and forearm } \\
\text { CRPS }\end{array}$ & None & $\begin{array}{l}200 \text { units BtxA in } 4 \text { mus- } \\
\text { cles in one participant, } \\
\text { and } 240 \text { units BtxA in } 3 \\
\text { muscles in the second } \\
\text { participant injected into } \\
\text { tender "trigger points" of } \\
\text { affected muscles. }\end{array}$ & $\begin{array}{l}\text { Pain score in the local area decreased } \\
\text { from } 10 \text { to } 2 \text { in the first participant } \\
\text { and from } 9 \text { to } 4 \text { in the second partici- } \\
\text { pant. Pain relief sustained in the first } \\
\text { participant for } 3 \text { years with quarterly } \\
\text { injections. } \\
\text { Both had improvement in discol- } \\
\text { oration, swelling and temperature } \\
\text { changes in the affected limb. }\end{array}$ & $\begin{array}{l}\text { Results are different } \\
\text { than, and comple- } \\
\text { mentary to, earlier } \\
\text { results by the same } \\
\text { group with intrader- } \\
\text { mal BtxA }\end{array}$ \\
\hline $\begin{array}{l}\text { Safarpour } \\
2010(29)\end{array}$ & $\begin{array}{l}8 \text { participants } \\
\text { with severe } \\
\text { CRPS affect- } \\
\text { ing all } 4 \text { limbs }\end{array}$ & $\begin{array}{l}6 \text { similar CRPS } \\
\text { participants } \\
\text { treated with } \\
\text { intradermal } \\
\text { injections with } \\
\text { normal saline }\end{array}$ & $\begin{array}{l}\text { Intradermal and subcu- } \\
\text { taneous injections, dose: } \\
40-100 \text { units }\end{array}$ & $\begin{array}{l}\text { No improvement in pain scores, or } \\
\text { secondary measures (quantitative } \\
\text { sensory testing, sleep quality, pain } \\
\text { impact, global satisfaction) }\end{array}$ & see discussion \\
\hline $\begin{array}{l}\text { Carroll } 2009 \\
\text { (30) }\end{array}$ & $\begin{array}{l}9 \text { participants } \\
\text { with lower } \\
\text { limb CRPS }\end{array}$ & $\begin{array}{l}\text { Same } 9 \\
\text { participants } \\
\text { (double-blinded } \\
\text { randomized } \\
\text { crossover study) } \\
\text { Placebo treat- } \\
\text { ment was } 10 \\
\text { mL of } 0.5 \% \\
\text { bupivacaine }\end{array}$ & $\begin{array}{l}\text { Cervical sympathetic } \\
\text { blocks using } 10 \mathrm{~mL} \text { of } \\
0.5 \% \text { bupivacaine and } 75 \\
\text { units of BtxA. }\end{array}$ & $\begin{array}{l}\text { Pain relieved for a longer duration } \\
\text { in treatment group (median } 71 \text { days) } \\
\text { as compared to controls (median } 10 \\
\text { days). }\end{array}$ & $\begin{array}{l}\text { Primary endpoint was } \\
\text { defined as return to } \\
\text { baseline pain level. }\end{array}$ \\
\hline $\begin{array}{l}\text { Lauretti } 2005 \\
\text { (31) }\end{array}$ & $\begin{array}{l}2 \text { CRPS } \\
\text { participants } \\
\text { (extent not } \\
\text { noted) with } \\
\text { marked hand } \\
\text { dystonia }\end{array}$ & None & $\begin{array}{l}75 \mathrm{IU} \text { of BtxA into } \\
\text { intrinsic finger flexors } \\
\text { and wrist }\end{array}$ & $\begin{array}{l}\text { All participants had improvement } \\
\text { in dystonia and pain. Motor relief } \\
\text { sustained for up to } 8 \text { months. }\end{array}$ & $\begin{array}{l}\text { Participants also } \\
\text { received a series of } \\
5 \text { ipsilateral stellate } \\
\text { ganglion blocks. Effect } \\
\text { of BtxA cannot be dis- } \\
\text { cerned separately, es- } \\
\text { pecially in the absence } \\
\text { of a control group. }\end{array}$ \\
\hline $\begin{array}{l}\text { Argoff } 2002 \\
(10)\end{array}$ & $\begin{array}{l}11 \text { par- } \\
\text { ticipants } \\
\text { with CRPS } \\
\text { affecting only } \\
\text { one upper } \\
\text { extremity }\end{array}$ & None & $\begin{array}{l}\text { Intramuscular, shoulder } \\
\text { girdle muscles. } \\
\text { Dose: } 25-50 \text { units }\end{array}$ & $\begin{array}{l}\text { All patients reported relief in pain } \\
\text { and improvement of skin color and } \\
\text { edema at } 6 \text { and } 12 \text { weeks }\end{array}$ & $\begin{array}{l}\text { Only study which } \\
\text { documented } \\
\text { changes in sudomotor } \\
\text { symptoms }\end{array}$ \\
\hline
\end{tabular}

\section{Conclusion}

There are several limitations of this study. These include its retrospective nature, the lack of a control group, and the possibility of a placebo effect. The study does not provide information on the efficacy of this treatment after one month. The current study was unable to identify predictors of pain relief after BtxA injection. Further studies are essential to determine these patient characteristics, and define subgroups of CRPS patients that are most likely to benefit from intramuscular BtxA injections.

This study is the largest study to date that documents a potentially useful therapy for a disease characterized by devastating and frequently intractable pain. In view of its limitations, this retrospective study provides data to justify a larger prospective randomized control trial. Further studies need to a) confirm these results, b) identify the subgroups of CRPS patients and modes of BtxA administration that optimize pain relief, c) assess 
changes in other symptoms of CRPS (sudomotor, vasomotor, trophic) and associated conditions (migraine), d) assess its use as an adjunct with other treatments such as ketamine to increase the efficacy of these medications, or to prolong their effect by decreasing the chronic pain stimuli that lead to central sensitization $(32,33)$.

\section{References}

1. Schwartzman RJ, Erwin KL, Alexander GM. The natural history of complex regional pain syndrome. Clin J Pain 2009; 25:273-280.

2. Birklein F. Complex regional pain syndrome. J Neurol 2005; 252:131-138.

3. Schwartzman RJ, Alexander GM, Grothusen J. Pathophysiology of complex regional pain syndrome. Expert Rev Neurother 2006; 6:669-681.

4. Aoki KR. Review of a proposed mechanism for the antinociceptive action of botulinum toxin type A. Neurotoxicology 2005; 26:785-793.

5. Park HJ, Lee Y, Lee J, Park C, Moon DE. The effects of botulinum toxin $A$ on mechanical and cold allodynia in a rat model of neuropathic pain. Can J Anaesth 2006; 53:470-477.

6. Ranoux D, Attal N, Morain F, Bouhassira D. Botulinum toxin type $A$ induces direct analgesic effects in chronic neuropathic pain. Ann Neurol 2008; 64:274283.

7. Casale R, Tugnoli V. Botulinum toxin for pain. Drugs R D 2008; 9:11-27.

8. Raj PP. Botulinum neurotoxin in chronic pain management. Pain Pract 2004; 4 Suppl 1:S68-S72.

9. Cui M, Khanijou S, Rubino J, Aoki KR. Subcutaneous administration of botulinum toxin $A$ reduces formalin-induced pain. Pain 2004; 107:125-133.

10. Argoff CE. A focused review on the use of botulinum toxins for neuropathic pain. Clin J Pain 2002; 18 (6 Suppl):S177$\mathrm{S} 181$.

11 Stanton-Hicks $M$, Jänig $W$, Hassenbusch S, Haddox JD, Boas R, Wilson P. Reflex sympathetic dystrophy: Changing concepts and taxonomy. Pain 1995; 63:127-133.

12. Farrar JT, Young JP, LaMoreaux L, Werth J, Poole RM. Clinical importance of changes in chronic pain intensity measured on an 11-point numerical pain rating scale. Pain 2001; 94:149-158.

13. Woolf CJ, Salter MW. Neuronal plasticity: Increasing the gain in pain. Science 2000; 288:1765-1769.

14. Kilo S, Harding-Rose C, Hargreaves KM, Flores CM. Peripheral CGRP release as a marker for neurogenic inflammation: A model system for the study of neuro- peptide secretion in rat paw skin. Pain 1997; 73:201-207.

15. Duggan MJ, Quinn CP, Chaddock JA, Purkiss JR, Alexander FCG, Doward S, Fooks SJ, Friis LM, Hall YHJ, Kirby ER, Leeds N, Moulsdale HJ, Dickenson A, Green GM, Rahman W, Suzuki R, Shone CC, Foster KA. Inhibition of release of neurotransmitters from rat dorsal root ganglia by a novel conjugate of a Clostridium botulinum toxin $\mathrm{A}$ endopeptidase fragment and Erythrina cristagalli lectin. J Biol Chem 2002; 277:34846-34852.

16. Purkiss J, Welch M, Doward S, Foster K. Capsaicin-stimulated release of substance $P$ from cultured dorsal root ganglion neurons: Involvement of two distinct mechanisms. Biochem Pharmaco 2000; 59:1403-1406.

17. Meng J, Wang J, Lawrence G, Dolly JO. Synaptobrevin I mediates exocytosis of CGRP from sensory neurons and inhibition by botulinum toxins reflects their anti-nociceptive potential. J Cell Sci 2007; 120:2864-2874.

18. van Hilten J, van de Beek WJ, Vein AA, van Dijk JG, Middelkoop HA. Clinical aspects of multifocal or generalized tonic dystonia in reflex sympathetic dystrophy. Neurology 2001; 56:1762-1765.

19. Schwartzman RJ, Kerrigan J. The movement disorder of reflex sympathetic dystrophy. Neurology 1990; 40:57-61.

20. van Hilten BJ, van de Beek WJ, Hoff I, Voormolen JH, Delhaas EM. Intrathecal baclofen for the treatment of dystonia in patients with reflex sympathetic dystrophy. N Engl J Med 2000; 343:625-630.

21. van Rijn MA, Munts AG, Marinus J, Voormolen JHC, de Boer KS, Teepe-Twiss IM, van Dasselaar NT, Delhaas EM, van Hilten JJ. Intrathecal baclofen for dystonia of complex regional pain syndrome. Pain 2009; 143:41-47.

22. Munts AG, van der Plas AA, Voormolen $\mathrm{JH}$, Marinus J, Teepe-Twiss IM, Onkenhout W, van Gerven JM, van Hilten JJ. Intrathecal glycine for pain and dystonia in complex regional pain syndrome. Pain 2009; 146:199-204.

23. Tugnoli V, Capone JG, Eleopra R, Quatrale R, Sensi M, Gastaldo E, Tola MR, Geppetti P. Botulinum toxin type A reduces capsaicin-evoked pain and neurogenic vasodilatation in human skin. Pain
2007; 130:76-83.

24. Gazerani P, Pedersen NS, Staahl C, Drewes AM, Arendt-Nielsen L. Subcutaneous Botulinum toxin type A reduces capsaicin-induced trigeminal pain and vasomotor reactions in human skin. Pain 2009; 141:60-69.

25. Carmichael NME, Dostrovsky JO, Charlton MP. Peptide-mediated transdermal delivery of botulinum neurotoxin type $A$ reduces neurogenic inflammation in the skin. Pain 2010; 149:316-324.

26. Yuan RY, Sheu JJ, Yu JM, Chen WT, Tseng IJ, Chang $\mathrm{HH}$, Hu CJ. Botulinum toxin for diabetic neuropathic pain: $A$ randomized double-blind crossover trial. Neurology 2009; 72:1473-1478.

27. Jeynes LC, Gauci CA. Evidence for the use of botulinum toxin in the chronic pain setting--a review of the literature. Pain Pract 2008; 8:269-276.

28. Safarpour D, Jabbari B. Botulinum toxin a (botox) for treatment of proximal myofascial pain in complex regional pain syndrome: Two cases. Pain Med 2010; 11:1415-1418.

29. Safarpour D, Salardini A, Richardson D, Jabbari B. Botulinum Toxin A for Treatment of Allodynia of Complex Regional Pain Syndrome: A Pilot Study. Pain Med 2010; 11:1411-1414.

30. Carroll I, Clark JD, Mackey S. Sympathetic block with botulinum toxin to treat complex regional pain syndrome. Ann Neurol 2009; 65:348-351.

31. Lauretti GR, Veloso FDS, Mattos ALD. [Functional rehabilitation and analgesia with botulinum toxin $A$ in upper limb complex regional pain syndrome type I: case reports.]. Rev Bras Anestesiol 2005; 55:207-211.

32. Sigtermans MJ, van Hilten JJ, Bauer MCR, Arbous MS, Marinus J, Sarton EY, Dahan A. Ketamine produces effective and long-term pain relief in patients with Complex Regional Pain Syndrome Type 1. Pain 2009; 145:304-311.

33. Kiefer RT, Rohr P, Ploppa A, Dieterich HJ, Grothusen J, Koffler S, Altemeyer KH, Unertl K, Schwartzman RJ. Efficacy of ketamine in anesthetic dosage for the treatment of refractory complex regional pain syndrome: An open-label phase II study. Pain Med 2008; 9:1173-1201. 